\title{
NY-ESO-1/MART-1 Peptide-pulsed Dendritic Cell Vaccine
}

\author{
National Cancer Institute
}

\section{Source}

National Cancer Institute. NY-ESO-1/MART-1 Peptide-pulsed Dendritic Cell Vaccine. NCI

Thesaurus. Code C120129.

A cell-based cancer vaccine composed of dendritic cells (DC) pulsed with peptides derived from the tumor-associated antigens human cancer/testis antigen NY-ESO-1 and melanoma antigen recognized by T-cells (MART-1/Melan-A), with potential immunostimulatory and antineoplastic activities. Upon administration, the NY-ESO1/MART -1-peptide pulsed DC vaccine may stimulate the immune system to mount an anti-tumor cytotoxic T-lymphocyte (CT L) response against NY-ESO-1/MART -1expressing tumor cells, which may result in tumor cell lysis. NY-ESO-1 is expressed both in normal testes and on the surfaces of various tumor cells. MART-1 is expressed by melanoma cells. 